\title{
The relationship between psychological factors and maternal social support to breastfeeding process
}

\author{
Mitra Jalal $^{1}$, Mahrokh Dolatian ${ }^{2}$, Zohreh Mahmoodi ${ }^{3}$, Roqayeh Aliyari ${ }^{4}$
}

${ }^{1}$ M.Sc. in Midwifery, Department of Midwifery and Reproductive Health, School of Nursing and Midwifery,
International Branch of Shahid Beheshti University of Medical Sciences, Tehran, Iran
${ }^{2}$ Assistant Professor, Department of Midwifery and Reproductive Health, School of Nursing and Midwifery, Shahid
Beheshti University of Medical Sciences, Tehran, Iran
${ }^{3}$ Assistant Professor, Faculty of Nursing and Midwifery, Department of Midwifery, Alborz University of Medical
Sciences, Karaj, Iran
${ }^{4}$ Ph.D. Student in Biostatics, Department of Biostatics, School of Medical Science, Tarbiat Modares University,
Tehran, Iran

\section{Type of article: Original}

\begin{abstract}
Introduction: Childbirth is a stressful factor that can trigger disorders such as depression in women. The various problems characteristic to the puerperal period make mothers more prone than ever to stress, anxiety and depression. The aim of this study was to determine relationship between psychological factors and social support and breastfeeding process in mothers presenting to healthcare centers in Shahrood, Iran.

Methods: The present cross-sectional study was conducted on 465 mothers with infants aged one to six months, presenting to Shahrood healthcare centers in 2015-16. Data were obtained using a researcher-designed demographic and breastfeeding questionnaire, the Beck Depression Inventory, Spielberger's State-Trait Anxiety Inventory, Cohen's Perceived Stress Scale and the Multidimensional Scale of Perceived Social Support. Data were analyzed in SPSS-18 using measures of central tendency, the Chi-square test, the t-test, Mann-Whitney's test and Fisher's exact test and Logistic Regression Model. The level of statistical significance was set at $\mathrm{p}<0.05$.

Results: The prevalence of exclusive breastfeeding was $68.4 \%$ in the study population. The results revealed a significant relationship between state and trait anxiety and exclusive breastfeeding $(\mathrm{p}=0.004$ and $\mathrm{p}=0.006$, respectively). According to the results of the logistic regression, each unit of increase in the mother's mean state of anxiety protects the chances of non-exclusive breastfeeding up to about $54 \%(\mathrm{OR}=0.462)$.

Conclusion: The findings suggest that maternal anxiety can reduce the chances of exclusive breastfeeding. It is therefore recommended to actively monitor and manage maternal anxiety in the postpartum period so as to support exclusive breastfeeding.

Keywords: Exclusive breastfeeding, Stress, Depression, Anxiety, Social support
\end{abstract}

\section{Introduction}

Pregnancy, childbirth and compatibility with the newborn may comprise the most sensitive developmental stage in the life of a woman (1). Just when she is expecting enjoyable experiences with the birth of her baby, the mother comes to struggle with unknown and unpleasant states such as anxiety, feelings of weakness and helplessness, lack of pleasure, sleep and appetite disorder, lack of confidence and feelings of inadequacy as a parent (2). A mental and emotional physiological crisis occurs at this point, that can cause confusion and maternal identity change. Meanwhile, in the puerperal period, the mother's loss of stored energy caused by fatigue, pharmacological effects, duration of delivery and problems developed during the processes of childbirth and lactation, make her more prone than ever to emotional crises and mood changes such as stress, anxiety and depression. The emotional crises and

\section{Corresponding author:}

Assistant Professor Dr. Mahrokh Dolatian, Department of Midwifery and Reproductive Health, School of Nursing and Midwifery, Shahid Beheshti University of Medical Sciences, Tehran, Iran.

Tel: +98.2188202517, Fax: +98.2188202517, Email: mhdolatian@gmail.com

Received: August 19, 2016, Accepted: December 20, 2016, Published: January 2017

iThenticate screening: November 12, 2016, English editing: January 03, 2017, Quality control: January 08, 2017

(C) 2017 The Authors. This is an open access article under the terms of the Creative Commons Attribution-NonCommercialNoDerivs License, which permits use and distribution in any medium, provided the original work is properly cited, the use is non-commercial and no modifications or adaptations are made. 
mood changes following childbirth can have a negative effect on the mother's parenting role and the infant's nutrition and growth (1). Proper nutrition in the early stages of life, is integral to the growth and development of infants, and the positive effect of breastfeeding on the growth and development of lactating infants have been extensively confirmed by researchers (3). Successful breastfeeding depends not only on physiological factors but also on the mother's social and psychological conditions (4). Studies have shown that mental disorders such as depression, anxiety and stress have a negative effect on human physiological functions such as breastfeeding. Some evidence suggests that maternal stress can prevent the milk letdown reflex (3). Postpartum depression is a mental disorder that alters the quality of the emotional relationship between mother and infant (5). Studies have reported the prevalence of postpartum depression as 9-31\% (6-8). A high perceived stress of 46.5\% (3) and a postpartum anxiety of $10-50 \%$ (9) have been reported in primiparous women (10). These disorders are themselves affected by other factors such as perceived social support. This factor has a significant impact on health and social functioning through its protective role against stress and anxiety. Mothers' health especially that of breastfeeding mothers, is of great importance due to the role the mother plays in the growth and development of her infant, and the overall assessment of the health status of breastfeeding mothers, in terms of postpartum mental disorders, is considered an important health indicator (3). The medical and healthcare personnel are responsible for making a rapid diagnosis and differentiation of these disorders in women. Given that the different studies conducted on the role of these psychological factors in exclusive breastfeeding have found disparate results in Iran $(3,11-16)$ and other countries (17-20), and since a few studies have examined the relationship of depression, anxiety, stress and social support to breastfeeding in Iran, the present study was conducted to determine the relationship of psychological factors and social support to the breastfeeding process in mothers, presenting to healthcare centers in Shahrood, Iran.

\section{Material and Methods}

\subsection{Study type, population and sampling Method}

The present cross-sectional study was conducted on 465 mothers with infants aged one to six months presenting to urban healthcare centers of Shahrood in 2015-16. The participants were selected through multistage cluster sampling. First, all the healthcare centers affiliated to Shahrood University of Medical Sciences were listed. Based on the number of centers and in proportion to the number of individuals covered by each center and the study sample size, each center was allocated a quota. Convenience sampling was ultimately performed every day for three months in these centers.

\subsection{Selection criteria}

\subsubsection{Inclusion criteria}

Iranian women with healthy infants without any congenital abnormalities or known diseases that prevent breastfeeding, aged one to six months, that have resided in Shahrood for at least the past year, with an active health record in health centers, and reading and writing literacy.

\subsubsection{Exclusion criteria}

The exclusion criteria were having mother or infant's serious medical condition that prevented breastfeeding.

\subsection{Instruments}

For data collection, the researcher used the researcher-made demographic and breastfeeding questionnaire, Spielberger's State-Trait Anxiety Inventory (STAI), Cohen's Perceived Stress Scale (PSS14), the Multidimensional Scale of Perceived Social Support (MSPSS) and Beck's Depression Inventory (BDI II).

\subsubsection{The researcher-made questionnaire}

The demographic and breastfeeding questionnaire had three sections, including a demographic information section, a section on the factors affecting exclusive breastfeeding regarding the mother, and a section on the factors regarding the infant. The validity of this questionnaire was confirmed through the content validity method and its reliability was confirmed through the test-retest method $(\mathrm{r}=0.84)$.

\subsubsection{STAI}

Spielberger's State-Trait Anxiety Inventory was standardized in 1970 by Spielberger et al. and consists of 40 selfreport items that assess state and trait anxiety separately. The first 20 items assess state anxiety and the next 20 assess trait anxiety; the items are all scored based on a four-point Likert scale from 1 to 4 . The scores for each of the subscales of the STAI, i.e. the state and the trait anxiety subscales, range from 20 to 80 . This inventory classifies people into three groups, namely a group with mild anxiety (20-40 points), a group with moderate anxiety (41-60 points) and a group with severe anxiety (61-80 points). Numerous studies have confirmed the validity and reliability of the inventory. Mahram examined the validity and reliability of the inventory among Iranians in 1993 in Mashhad (21). The reliability of the inventory for state anxiety was 0.91 and for trait anxiety was 0.90 (22). 


\subsubsection{PSS14}

The Perceived Stress Scale was developed in 1983 by Cohen et al. and is used to assess general perceived stress over the past month. The scale consists of 14 items, including seven negative items indicating the inability to cope with stress and seven positive items indicating a good compatibility with stressors. The scale is scored based on a fivepoint Likert scale from 0 to 4 . The lowest score obtained is zero and the highest is 56 . Higher scores indicate a greater perceived stress (23). A Cronbach's alpha coefficient of 0.81 was obtained for this scale in women (3).

\subsubsection{MSPSS}

The Multidimensional Scale of Perceived Social Support was developed in 1988 by Zimet et al., to assess perceived social support, and the Persian version of the scale was developed in 2009 by Salimi et al (24). This scale consists of 12 items that are scored based on a Likert scale and that assess three subscales, including perceived support from family (4 items), perceived support from significant others (4 items) and perceived support from friends (4 items). All the items in this scale are scored based on a seven-point likert scale from 1 to 7 . The minimum score obtained in the scale is 12 and the maximum is 84 . Scores of 13-48 indicate a low social support, scores of 49-68 indicate moderate social support and scores of 69-84 indicate a high social support. The reliability of this scale has been confirmed in several studies with a Cronbach's alpha coefficient of $0.86 \%$ to $0.9 \%$ for the subscales and $0.86 \%$ for the entire scale $(24,25)$.

\subsubsection{BDI II}

The Beck Depression Inventory was first developed in 1961 by Beck et al., and is a 21 -item self-report questionnaire made to assess the attitudes and symptoms of depression in patients. The participants respond to the inventory on a four-point scale from 0 to 3 . The scores obtained range from a minimum of zero to a maximum of 63 . This inventory thus determines varying degrees of depression, including mild (scores of 14-19), moderate (scores of 20-28) and high (scores of 29-63) depression. The reliability and validity of the inventory have been reviewed and confirmed in several other studies $(26,27)$. A Cronbach's alpha coefficient of 0.86 was obtained for this scale (28).

\subsection{Research Ethics}

After approval by the ethics committee of Shahrood University of Medical Sciences under the ethics code IR.SHMU.REC.1394.71, dated 15/07/2015, and obtaining permission from the relevant units and providing explanation about the study objectives, sampling was performed on the eligible and willing mothers who had submitted their written consent forms and data collection thus began. The subjects were informed that their participation was voluntary, the questionnaires were anonymous and all their information would be kept confidential.

\subsection{Statistical Analysis}

The data obtained were ultimately analyzed in SPSS-18 using measures of central tendency, the Chi-square test, the t-test, Mann-Whitney's test, Fisher's exact test and Logistic Regression Model. The level of statistical significance was set at $\mathrm{p}<0.05$.

\section{Results}

The majority of the participating mothers were housewives (84.1\%) and had university education (43.1\%) and a mean age of $28.92 \pm 5.22$ years. Their husbands had a mean age of $38.82 \pm 5.87$ years, were mostly self-employed and had university education in $37.4 \%$ of the cases. A total of $89.7 \%$ of the deliveries were full-term and the birth weight of more than $90 \%$ of the infants was between 2500 and $4000 \mathrm{~g}$. The mean prevalence of exclusive breastfeeding was $68.4 \%$ in the study population, and reached $36.6 \%$ by six months old, from $80.7 \%$ in the first month (Table 1 ). The results of the study showed that $71 \%$ of the mothers were normal, in terms of depression. State anxiety was high in $21.7 \%$ of the mothers and trait anxiety was high in $20.2 \%$. A total of $35.7 \%$ of the mothers had high social support and $52.5 \%$ had medium social support. A total of $92.9 \%$ of the mothers had mild stress. A significant relationship was observed between state and trait anxiety and exclusive breastfeeding $(\mathrm{p}=0.004$ and $\mathrm{p}=0.006$, respectively); (Table 2). The logistic regression analysis was used in this study to determine the relationship of personal, social and psychological factors to exclusive breastfeeding. The Hosmer-Lemeshow test was used to investigate the goodness of fit for the logistic regression model and the model was found to have a goodness of fit. The variables with a significance level of $2 \%(\mathrm{p} \leq 0.2)$, were introduced into the model in one stage. The model was significantly reliable $(\mathrm{p}<0.05)$. The analysis was carried out based on the Enter method (Table 3). Of the variables that became significant, two factors, namely the infants' weight loss in the past months $(\mathrm{OR}=2.271)$ and birth weight $<2500$ $(\mathrm{OR}=5.698)$, increased the chances of non-exclusive breastfeeding 2.7 and 5.6 times more than the other variables, respectively. With an increase in the mothers' mean state anxiety $(\mathrm{OR}=0.462)$, the chances of non-exclusive breastfeeding are protected up to about 54\%. 
Table1. Samples distribution and association between demographic and obstetric variables, and variables related to infant with exclusive breastfeeding $(n=465)$

\begin{tabular}{|c|c|c|c|c|c|}
\hline \multirow{2}{*}{\multicolumn{3}{|c|}{ Variables }} & \multirow{2}{*}{\multicolumn{2}{|c|}{ Exclusive breastfeeding }} & \multirow{4}{*}{$\begin{array}{l}\mathrm{p}- \\
\text { value }\end{array}$} \\
\hline & & & & & \\
\hline & & & \multirow{3}{*}{$\begin{array}{l}\text { yes } \\
\mathrm{n}(\%) / \\
\text { Mean } \pm \text { SD } \\
28.82(5.26)\end{array}$} & \multirow{2}{*}{$\begin{array}{l}\text { no } \\
\mathrm{n}(\%) / \\
\text { Mean } \pm \mathrm{SD}\end{array}$} & \\
\hline & & & & & \\
\hline \multirow[t]{8}{*}{ Mother } & \multicolumn{2}{|l|}{ Age (year) } & & $29.15(5.14)$ & 0.521 \\
\hline & \multirow[t]{3}{*}{ Education } & $\begin{array}{l}\text { Under high school } \\
\text { diploma }\end{array}$ & $75(70.1)$ & $32(29.9)$ & \multirow[t]{3}{*}{0.322} \\
\hline & & $\begin{array}{l}\text { High school } \\
\text { diploma }\end{array}$ & $119(70.7)$ & $47(28.3)$ & \\
\hline & & College education & $124(64.6)$ & $68(35.4)$ & \\
\hline & \multirow[t]{2}{*}{ Job } & Housewife & $268(68.5)$ & $123(31.5)$ & \multirow[t]{2}{*}{0.892} \\
\hline & & Employed & $50(67.6)$ & $24(32.4)$ & \\
\hline & \multirow[t]{2}{*}{ Field of study } & Medical & $123(64.4)$ & $68(35.6)$ & \multirow[t]{2}{*}{0.075} \\
\hline & & Non-medical & $195(71.2)$ & $79(28.8)$ & \\
\hline \multirow[t]{9}{*}{ Father } & \multicolumn{2}{|l|}{ Age (year) } & $32.68(6.01)$ & $29.15(5.14)$ & 0.521 \\
\hline & \multirow[t]{3}{*}{ Education } & $\begin{array}{l}\text { Under high school } \\
\text { diploma }\end{array}$ & $87(70.2)$ & $37(29.8)$ & \multirow[t]{3}{*}{0.589} \\
\hline & & $\begin{array}{l}\text { High school } \\
\text { diploma }\end{array}$ & $117(70.1)$ & $50(29.9)$ & \\
\hline & & College education & $114(65.5)$ & $60(34.5)$ & \\
\hline & \multirow[t]{3}{*}{ Job } & Employee & $99(66.9)$ & $49(33.1)$ & \multirow{3}{*}{0.806} \\
\hline & & Self- employed & $160(68.4)$ & $74(31.6)$ & \\
\hline & & Other & $59(71.1)$ & $24(28.9)$ & \\
\hline & \multirow[t]{2}{*}{ Field of study } & Medical & $116(65.2)$ & $62(34.8)$ & \multirow[t]{2}{*}{0.142} \\
\hline & & Non- medical & $202(70.4)$ & $85(29.6)$ & \\
\hline \multicolumn{3}{|c|}{ Family income (I.R. Rial) } & $\begin{array}{l}12100000 \\
(7580000)\end{array}$ & $\begin{array}{l}13900000 \\
(10670000)\end{array}$ & 0.056 \\
\hline \multirow[t]{12}{*}{ Child } & \multicolumn{2}{|l|}{ Age (month) } & $2.88(1.64)$ & $4.22(1.93)$ & 0.000 \\
\hline & Gender & Female & $160(66.4)$ & $81(33.6)$ & 0.195 \\
\hline & & Male & $158(70.5)$ & $66(29.5)$ & \\
\hline & Gestational age at birth & $<37$ & $31(50)$ & $31(50)$ & 0.001 \\
\hline & (week) & $\geq 37$ & $287(71.2)$ & $116(28.8)$ & \\
\hline & Birth weight & $<2500$ & $10(34.5)$ & $19(65.6)$ & 0.000 \\
\hline & (gram) & $2500-4000$ & $294(70.2)$ & $125(29.8)$ & \\
\hline & & $>4000$ & $14(82.4)$ & $3(17.6)$ & \\
\hline & Infants' weight loss in the & Yes & $19(46.3)$ & $22(53.7)$ & 0.002 \\
\hline & past months & No & $299(70.5)$ & $125(29.5)$ & \\
\hline & Using sugar water & Yes & $66(60.6)$ & $43(36.4)$ & 0.030 \\
\hline & & No & $252(70.8)$ & $104(29.2)$ & \\
\hline Pregnancy and & Pregnancy increase weight & $\mathrm{kg})$ & $11.90(4.10)$ & $13.35(4.88)$ & 0.002 \\
\hline childbirth & Number of newborn & Single & $313(70)$ & $134(30)$ & 0.000 \\
\hline & & Twin & $5(27.8)$ & $13(72.2)$ & \\
\hline & Rooming in & Yes & $290(71.4)$ & $116(28.6)$ & 0.000 \\
\hline & & No & $28(47.5)$ & $31(52.5)$ & \\
\hline & Kind of baby's first & Breast milk & $292(69.5)$ & $128(30.5)$ & 0.194 \\
\hline & feeding & Serum therapy & $14(63.3)$ & $8(36.4)$ & \\
\hline & & Other & $12(52.2)$ & $11(47.8)$ & \\
\hline History of exclu & breastfeeding & Yes & $150(71.1)$ & $61(28.9)$ & 0.001 \\
\hline & & No & $10(35.8)$ & $16(61.5)$ & \\
\hline
\end{tabular}


Table 2. Samples distribution and association between psychological factors and social support with exclusive breastfeeding $(\mathrm{n}=465)$

\begin{tabular}{|c|c|c|c|c|c|c|}
\hline \multicolumn{3}{|l|}{ Variable } & \multirow{3}{*}{$\mathrm{n}(\%)$} & \multicolumn{2}{|c|}{ exclusive breastfeeding } & \multirow[t]{3}{*}{ p-value } \\
\hline & & & & \multirow{2}{*}{$\begin{array}{l}\text { Yes } \\
\mathrm{n}(\%)\end{array}$} & \multirow{2}{*}{$\begin{array}{l}\text { No } \\
\mathrm{n}(\%)\end{array}$} & \\
\hline & & & & & & \\
\hline \multirow[t]{6}{*}{ Anxiety } & \multirow[t]{3}{*}{ Trait anxiety } & Mild & $148(31.8)$ & $116(78.4)$ & $32(21.6)$ & \multirow{3}{*}{0.006} \\
\hline & & Moderate & $223(48.0)$ & $143(61.1)$ & $80(35.9)$ & \\
\hline & & Severe & $94(20.2)$ & $59(62.8)$ & $35(37.2)$ & \\
\hline & \multirow[t]{3}{*}{ State anxiety } & Mild & $182(39.1)$ & $136(74.7)$ & $46(25.3)$ & \multirow{3}{*}{0.004} \\
\hline & & Moderate & $182(39.1)$ & $126(69.2)$ & $56(30.8)$ & \\
\hline & & Severe & $101(21.8)$ & $56(55.4)$ & 45 (44.6) & \\
\hline \multirow{3}{*}{\multicolumn{2}{|c|}{ Stress }} & Mild & $432(92.9)$ & $300(69.4)$ & $132(30.6)$ & \multirow[t]{3}{*}{0.760} \\
\hline & & Moderate & $33(7.1)$ & $18(54.5)$ & $15(45.5)$ & \\
\hline & & Severe & - & - & - & \\
\hline \multirow{4}{*}{\multicolumn{2}{|c|}{ Depression }} & Normal & $330(71.0)$ & $235(71.2)$ & $95(28.8)$ & \multirow[t]{4}{*}{0.065} \\
\hline & & Mild & $61(13.1)$ & $41(67.2)$ & $20(32.8)$ & \\
\hline & & Moderate & $53(11.4)$ & $28(52,8)$ & $25(47.2)$ & \\
\hline & & Severe & $21(4.5)$ & $14(66.7)$ & $7(33.3)$ & \\
\hline \multirow{3}{*}{\multicolumn{2}{|c|}{ Social support }} & Low & $55(11.8)$ & $30(54.5)$ & $25(45.5)$ & \multirow[t]{3}{*}{0.063} \\
\hline & & Moderate & $244(52.5)$ & $172(70.5)$ & $72(29.5)$ & \\
\hline & & High & $166(35.7)$ & $116(69.9)$ & $50(30.1)$ & \\
\hline
\end{tabular}

Table 3. Predictive factors of exclusive breastfeeding among 1-6 months old breast feeders by logistic regression analysis $(n=465)$; Method $=$ Enter, Hosmer-Lemeshow test: $\left(\chi^{2}=9.902, p=0.272\right)$.

\begin{tabular}{|c|c|c|c|c|}
\hline \multicolumn{2}{|l|}{ Variable } & B & $p$-value & $\mathrm{OR}$ \\
\hline \multicolumn{2}{|l|}{ Pregnancy increased weight $(\mathrm{kg})$} & 0.80 & 0.004 & 1.08 \\
\hline \multicolumn{2}{|l|}{ Child age (month) } & 0.42 & 0.000 & 1.52 \\
\hline \multirow[t]{2}{*}{ Number of newborn } & Twin & & & (Ref) \\
\hline & Single & -1.76 & 0.006 & 0.17 \\
\hline \multirow[t]{3}{*}{ Birth weight (gram) } & $>4000$ & & & (Ref) \\
\hline & $<2500$ & 1.74 & 0.048 & 5.69 \\
\hline & $2500-4000$ & 0.38 & 0.592 & 1.46 \\
\hline \multirow[t]{2}{*}{ Using sugar water } & No & & & (Ref) \\
\hline & Yes & 0.55 & 0.041 & 1.73 \\
\hline \multirow[t]{2}{*}{ Infants' weight loss in the past months } & No & & & (Ref) \\
\hline & Yes & 0.82 & 0.038 & 2.27 \\
\hline \multirow[t]{3}{*}{ Kind of the first feeding } & Serum therapy & & & (Ref) \\
\hline & Breast milk & 0.53 & 0.291 & 1.70 \\
\hline & Other & 0.38 & 0.495 & 1.46 \\
\hline \multirow[t]{3}{*}{ State anxiety } & Severe & & & (Ref) \\
\hline & Low & -0.78 & 0.093 & 0.45 \\
\hline & Moderate & -0.77 & 0.036 & 0.46 \\
\hline \multirow[t]{3}{*}{ Trait anxiety } & Severe & & & (Ref) \\
\hline & Low & 0.07 & 0.897 & 1.07 \\
\hline & Moderate & 0.73 & 0.076 & 2.09 \\
\hline \multirow[t]{4}{*}{ Depression } & Severe & & & (Ref) \\
\hline & Normal & 0.32 & 0.658 & 1.37 \\
\hline & Low & -0.02 & 0.969 & 0.97 \\
\hline & Moderate & 1.00 & 0.151 & 2.71 \\
\hline \multirow[t]{3}{*}{ Social support } & High & & & (Ref) \\
\hline & Low & 0.46 & 0.268 & 1.58 \\
\hline & Moderate & -0.17 & 0.493 & 0.83 \\
\hline \multirow[t]{2}{*}{ Stress } & moderate & & 0.258 & (Ref) \\
\hline & low & 0.25 & 0.641 & 1.29 \\
\hline
\end{tabular}




\section{Discussion}

The results of this study confirm the significant relationship between mothers' state and trait anxiety after childbirth and exclusive breastfeeding. According to the logistic regression analysis, the mothers' mean state anxiety reduces the chances of exclusive breastfeeding. Anxiety and worry are unpleasant and uncertain emotions (29) that comprise one of the common complications of stress (30). Stress and anxiety are biological-hormonal responses to the psychosocial environment that are affected by the hypothalamic-pituitary-adrenal axis activity, and increase catecholamines such as epinephrine (31). Since this axis is more sensitive to stress in postpartum compared to ordinary women (11), it leads to reduced prolactin and oxytocin secretion, and thereby reduced milk supply when breastfeeding (32). The findings of this study are consistent with the results obtained by Yasemi and Razjooyan (11), Adedinsewo et al. (33) and Paul et al. (34). Nevertheless, Mezzacappa et al. (35) and Jager et al. (20) did not observe any such significant relationships in their studies. The disparity of findings may be attributed to differences in the study population and level of education. The present study was conducted in an urban population, and more than $41 \%$ of the mothers had a university education; it is possible for educated urban mothers to develop greater anxiety due to the availability and greater use of new sources of data and thereby their greater attention to prenatal and postpartum care and newborn care. The lack of adequate preparation for parental role attainment and for accepting the responsibility of taking care of the newborn in $49 \%$ of the samples who were having their first newborn, may have also triggered greater concern and anxiety in the mothers. Since more than $55 \%$ of the deliveries in this study were performed by $\mathrm{C}$-section, the anxiety of undergoing surgery and its complications may have contributed to anxiety levels in the postpartum mothers. The present study found no significant relationships between postpartum depression and exclusive breastfeeding, which is consistent with the results, obtained by Yasemi and Razjooyan (11) and O'Brien et al. (36). Nevertheless, Roubintan et al. found a significant relationship between infants' nutrition and postpartum depression (14). Given the relatively similar mean age of the mothers participating in all these studies, the disparity of findings may be attributed to differences in the time of assessment. In studies in which more time has passed from the mother's labor and delivery, depression appears to have subsided, or somehow overcome with time. It also seems that the passage of time and the mothers' breastfeeding and physical contact with their newborn, play a major role in improving the mothers' emotional state and their adjustment to their postpartum conditions. The findings of this study showed the lack of significant relationships between exclusive breastfeeding and stress, which is consistent with the results obtained by O'Brien (36) and Jager (20). In one study, Insaf found maternal stress to be one of the impeding factors of exclusive breastfeeding; however, it should be noted that most of the mothers investigated in Insaf's study were young and had a low income and low level of education (37). Given the various findings about the inhibitory role of stress in the flow of breast-milk (3), and, since Rosier found low income to be a stressor affecting health behavior (38), it can be argued that income is the underlying factor that makes the relationship between stress and exclusive breastfeeding a significant one in Insaf's study. Biological-physical factors affect breastfeeding; these factors are themselves influenced by maternal feelings, peace, self-confidence and beliefs, and the mother's beliefs are inevitably developed under the influence of a network of social relations, including the family. Studies have shown that the social support given by those around, including the mother's own mother, her husband, the doctor and the healthcare providers, plays a decisive role in the process of breastfeeding (16). The present study found no significant relationships between social support and exclusive breastfeeding, which is consistent with the results obtained by Akman et al. (39), although this factor has been proposed as an impeding factor in other studies (40). The disparity of findings may be attributed to the increased awareness of mothers caused by their higher levels of education, their housewife status in more than $80 \%$ of the cases and the consequent lack of stress and anxiety about returning to work and having professional duties to fulfill, and previous breastfeeding experience in more than half $(51 \%$ of the mothers had two children or more). The cultural differences at play between different societies should not be neglected. Of the variables that were entered into the regression model, two factors, namely low birth weight $(<2500$ gr) and infant weight loss, had the greatest negative effect on the chances of exclusive breastfeeding. In one study, Mohsenzadeh et al. reported the main reason for the failure of exclusive breastfeeding as the drop in the growth curve of the infant and his reduced growth (41). Yaghini et al. (42) and Rahmatnejad and Bastani (43) propose low birth weight (LBW) as one of the reasons for the premature discontinuation of breastfeeding. The reason for this phenomenon may be the comparisons made by the mother about the LBW of her infant and appearance with that of other children's, and the resulting concerns about the inadequacy of her milk supply and its low quality. These concerns force the mothers to feed their newborns with other foods. The limitations of this study include the use of self-report questionnaires for surveying psychological factors. These tools increase the possibility of inaccurate responses (44). Other limitations that may have had the same effect, include the use of general items in the questionnaires and the occasional incomprehensibility of the items to the mothers. 


\section{Conclusions}

The results of this study showed a significant relationship between maternal postpartum anxiety and exclusive breastfeeding, as one unit of increase in the mean state anxiety of the mothers protected the chances of nonexclusive breastfeeding up to about 54\%. Developing appropriate strategies therefore, appears essential for promoting policymakers' and healthcare providers' interest in certain demographic and psychological characteristics in mothers, that can help improve breastfeeding. Psychological screening during pregnancy for identifying women at risk through combining mental health clinics with postpartum clinics is necessary and strongly recommended. Since previous studies on the subject have shown the multi-factorial nature of the discussed mental disorders, future studies are recommended to consider the effects of these factors.

\section{Acknowledgments:}

The authors would like to express their gratitude to all those who cooperated in this study, including the Research Deputy of Shahrood University of Medical Sciences, the personnel at Shahrood healthcare centers and all the kind mothers who patiently cooperated in the data collection. This work is part of a Master of Science Degree in Midwifery thesis.

\section{Conflict of Interest:}

There is no conflict of interest to be declared.

\section{Authors' contributions:}

All authors contributed to this project and article equally. All authors read and approved the final manuscript.

\section{References:}

1) Rahmani F, Seyedfatemi N, Asadollahi M, Seyedrasooli A. Predisposing factors of postpartum depression. Iran Journal of Nursing. 2011; 24(72): 78-87.

2) Lashgaripour K, Bakhshni M, Hokmabadi S, Sajjadi A, Safarzadeh A. Postpartum depression and related factors: A 4.5 months study. Journal of Fundamentals of Mental Health. 2012; 13(4(52)): 404-12.

3) Bastani F, Rahmatnejad L, Jahdi F, Haghani H. Self-sufficiency and perceived stress in nulliparous mothers. Iran Journal of Nursing. 2008; 21(54): 9-24.

4) Krouse AM. The family management of breastfeeding low birth weight infants. J Hum Lact. 2002; 18(2): 155-65. doi: 10.1177/089033440201800207. PMID: 12033077.

5) Nehbandani S, Nahidi F, Kariman N, Nasiri M. Relationship between gestational diabetes and postpartum depression. Iranian Journal of Obstetrics Gynecology and Infertility. 2016; 19(7): 18-24. doi: 10.22038/ijogi.2016.6969.

6) Bahadoran P, Mohamadalibeigi N. Stress and anxiety in pregnancy. Iranian Journal of Nursing \& Midwifery Research. 2005; 10(2): 41-6.

7) Khodadadi N, Mahmoodi H, Mirhagjoo N. Postpartum depression relationship with some psychosocial effects in mothers. J Ardabil Univ Med Sci. 2008; 8(2): 142-8.

8) Borra C, Iacovou M, Sevilla A. New evidence on breastfeeding and postpartum depression: the importance of understanding women's intentions. Maternal and child health journal. 2015; 19(4): 897-907. doi: 10.1007/s10995-014-1591-z.

9) Wenzel A, Haugen EN, Jackson LC, Brendle JR. Anxiety symptoms and disorders at eight weeks postpartum. J Anxiety Disord. 2005; 19(3): 295-311. doi: 10.1016/j.janxdis.2004.04.001. PMID: 15686858.

10) Mirghaforvand M, Hasanpoor S, Bani S, Yahyavi F. Perceived social support in infertile couples and its individual-social predictors. Journal of Mazandaran University of Medical Sciences. 2014; 23(1): 213-23.

11) Yasemi MT, Razjooyan K. Relationship of mental disorder anxiety and depression with cessation of breastfeeding. Journal of Guilan University of Medical Sciences. 2001; 10(39-40): 1-7.

12) Moudi A, Tafazoli M, Boskabadi H, Ebrahimzadeh S, Salehiniya H. Comparing the effect of peer support and training by healthcare providers on women's breastfeeding self-efficacy. Journal of Midwifery and Reproductive Health. 2016; 4(1): 488-97. doi: 10.22038/jmrh.2016.5629.

13) Ghasemzadeh MJ, Masomi A, Karamali J, Sharif MR, Mohabi S. Association of postpartum depression with exclusive breastfeeding. Journal of Health Research. 2013; 9(6): 579-86.

14) Roubintan N, Esmaeilpour K, Mahmoud Aliloo M, Seyedrasool E. The relationship of type of delivery and infant feeding with postpartum depression. Medical journal of Tabriz University. 2012; 34(3): 52-6.

15) Bakhshi M, Kordi M, Esmaeeli H. The effect of continuous support during labor on the onset of lactogenesis stage II in primiparas. J Mazandaran Univ Med Sci. 2015; 25(130): 153-8. 
16) Elahidoost S, Rabbani A, Shams B. Women, Motherhood and Breastfeeding. Journal of Women Studies. 2013; 4(1): 1-38.

17) Britton JR. Postpartum anxiety and breast feeding. J Reprod Med. 2007; 52(8): 689-95. PMID: 17879829.

18) Li J, Kendall GE, Henderson S, Downie J, Landsborough L, Oddy WH. Maternal psychosocial well being in pregnancy and breastfeeding duration. Acta Paediatr. 2008; 97(2): 221-5. doi: 10.1111/j.16512227.2007.00602.x. PMID: 18254911.

19) McKee MD, Zayas LH, Jankowski KRB. Breastfeeding intention and practice in an urban minority population: relationship to maternal depressive symptoms and mother-infant closeness. Journal of reproductive and infant psychology. 2004; 22(3): 167-81. doi: 10.1080/02646830410001723751.

20) de Jager E, Broadbent J, Fuller-Tyszkiewicz M, Skouteris H. The role of psychosocial factors in exclusive breastfeeding to six months postpartum. Midwifery. 2014; 30(6): 657-66. doi: 10.1016/j.midw.2013.07.008. PMID: 23932036.

21) Mahram B. Standardization of State and Trait Anxiety Spielberger Test. Master of Sciences. Ferdosi University of Mashhad. 1993.

22) Shahhosseini Z, Abedian K, Azimi H. Role of anxiety during pregnancy in preterm delivery. ZUMS. 2008; 16(63): 85-92.

23) Cohen S, Kamarck T, Mermelstein R. A global measure of perceived stress. J Health Soc Behav. 1983; 24(4): 385-96. doi: 10.2307/2136404. PMID: 6668417.

24) Salimi AR, Joukar B, Nikpour R. Internet and communication: Perceived social support and loneliness as antecedent variables. Journal of Psychological Studies. 2009; 5(3): 81-102.

25) Bruwer B, Emsley R, Kidd M, Lochner C, Seedat S. Psychometric properties of the Multidimensional Scale of Perceived Social Support in youth. Compr Psychiatry. 2008; 49(2): 195-201. doi: 10.1016/j.comppsych.2007.09.002. PMID: 18243894.

26) Talaei A, Asna AA, Mohareri F, Rezaei AA, Mirshojaeian M. Depression in unstable angina in patients in Iran: a case-control study. The Quarterly Journal of Fundamentals Of Mental Health. 2009; 10(4(40)): 299304.

27) Rajabi G, Karjo KS. Psychometric properties of a persian-language version of the Beck Depression Inventory-second edition (BDI-II-persian). Journal of Training Measurement. 2013; 3(10): 139-57.

28) Ghassemzadeh H, Mojtabai R, Karamghadiri N, Ebrahimkhani N. Psychometric properties of a persian language version of the Beck Depression Inventory - Second edition: BDI - II - persian. Depression and anxiety. 2005; 21(4): 185-92. doi: 10.1002/da.20070. PMID: 16075452.

29) Benjamin J, Sodack M. Comprehensive textbook of psychiatry. New York: Lippincott; 2010.

30) Atkinson RL. Hilgard's introduction to psychology: Harcourt Brace College Publishers Philadelphia PA; 1996.

31) Fajardo MC, Florido J, Villaverde C, Oltras CM, Gonzalez-Ramirez AR, Gonzalez-Gomez F. Plasma levels of $\beta$-endorphin and ACTH during labor and immediate puerperium. European Journal of Obstetrics \& Gynecology and Reproductive Biology. 1994; 55(2): 105-8. doi: 10.1016/0028-2243(94)90062-0.

32) Poorafshar F, Salari P, Azarpajoo H, Esmaeili H. Effect labor of preparation first women during pregnancy and childbirth anxiety the social security clinics in Mashhad in 2000. J Shahid Sadoghi Yazd University of Medical Sciences. 2005; 13(3): 39-44.

33) Adedinsewo DA, Fleming AS, Steiner M, Meaney MJ, Girard AW. Maternal anxiety and breastfeeding findings from the MAVAN (Maternal Adversity, Vulnerability and Neurodevelopment) study. J Hum Lact. 2014; 30(1): 102-9. doi: 10.1177/0890334413504244. PMID: 24065719.

34) Paul IM, Downs DS, Schaefer EW, Beiler JS, Weisman CS. Postpartum anxiety and maternal-infant health outcomes. Pediatrics. 2013; 131(4): e1218-24. doi: 10.1542/peds.2012-2147. PMID: 23460682.

35) Mezzacappa ES, Katkin ES. Breastfeeding is associated with reduced perceived stress and negative mood in mothers. Health Psychol. 2002; 21(2): 187-93. doi: 10.1037/0278-6133.21.2.187. PMID: 11950109.

36) O'Brien M, Buikstra E, Hegney D. The influence of psychological factors on breastfeeding duration. J Adv Nurs. 2008; 63(4): 397-408. doi: 10.1111/j.1365-2648.2008.04722.x. PMID: 18727767.

37) Insaf TZ, Fortner RT, Pekow P, Dole N, Markenson G, Chasan-Taber L. Prenatal stress, anxiety, and depressive symptoms as predictors of intention to breastfeed among Hispanic women. J Womens Health (Larchmt). 2011; 20(8): 1183-92. doi: 10.1089/jwh.2010.2276. PMID: 21668379.

38) Rozier B. Fundamentals of Nursing. 7th ed. Philadelohia: Lippincott; 2004. 
39) Akman I, Kuscu MK, Yurdakul Z, Özdemir N, Solakoğlu M, Orhon L, et al. Breastfeeding duration and postpartum psychological adjustment: role of maternal attachment styles. J Paediatr Child Health. 2008; 44(6): 369-73. doi: 10.1111/j.1440-1754.2008.01336.x. PMID: 18476931.

40) Dodgson JE, Duckett L, Garwick A, Graham BL. An ecological perspective of breastfeeding in an indigenous community. J Nurs Scholarsh. 2002; 34(3): 235-41. doi: 10.1111/j.1547-5069.2002.00235.x. PMID: 12237985.

41) Mohsenzadeh A, Mardani M, Shahkarami K, Ebrahimzadeh F. Failure factors of exclusive breast feeding during the first 6 months of infants' life in Khorramabad. Yafteh. 2008; 10(1): 55-61.

42) Yaghini SO, Khameh S, Danesh F, Modaresi MR, Saneian H. Determinants of exclusive breast milk feeding of infants in Isfahan, Iran. Journal of Isfahan Medical School. 2011; 28(117): 1-14.

43) Rahmatnejad L, Bastani F. Factors associated with discotinuation of exclusive breast feeding by first time mothers. Iran Journal of Nursing. 2011; 24(71): 42-53.

44) Masoudnia E. Relationship between perceived social support and risk of postpartum depression disorder. Iran Journal of Nursing. 2011; 24(70): 8-18. 